\title{
The Fifth Element: Social Class and the Sociology of
} Anorexia

Epidemiological research has identified a significant association between upper or middle class membership and a woman's probability of becoming anorexic, but the extant literature has yet to address the social processes underlying this association. In order to fill this gap, this paper frames anorexia as a deviant career that entails the adoption of an anorexic set of practices and orientations that may be recognized as a distinctive type of Bourdieuian habitus. Drawing upon on ethnographic fieldwork and qualitative interviews conducted in France, this paper argues that the set of practices and orientations acquired through an anorexic career builds upon practices and orientations clearly identified with middle and upper class status.

ANOREXIC CAREER - DEVIANT CAREER - BODY - EATING DISORDERS (SOCIAL FACTORS) - FOOD - HABITUS - HOSPITAL - RESISTANCE 
A great deal has been written about the socio-cultural bases of Anorexia Nervosa. Indeed, perhaps too much for the preferences of scholars in the field: in an appraisal of a recent book, one described herself as 'someone in feminist theory, women's studies, and medical discourse analysis who had hoped she would go to her grave without ever having to read another word about anorexia nervosa' (Treichler, in Gremillion, 2003). Yet, despite an abundance of sociological writing on the subject of Anorexia, gaps remain in this literature. Surprisingly enough, sociologists researching Anorexia have shied away from the one element that is traditionally theirs to study: social class. Instead, social scientists have geared their focus towards four alternative elements: a gender bias rendering women more at risk than men, the most affected age-group (adolescent girls), historical time periods (especially from the 19th century onwards, and especially since the 1960s), and cultural-geographical boundaries (Western countries and Japan). Compared to the abundance of research on the above four themes, and considering the relevance and specificity of class analysis in sociological thought, the class position of anorexic individuals has been understudied, causing social class to have a limited role in theorizing about eating disorders.

This paper provides an analysis of anorexia that puts this 'Fifth Element' in plain light while elaborating a purely sociological analysis of anorexia. It also illustrates the usefulness of approaching anorexia as a deviant career of conversion while reconstructing the 'social space' of class culture, class dispositions and class practices in which this 
career develops. This will be done by identifying anorexic food practices and body uses as those of the upper and middle classes, revealing the anorexic conversion as a particularly class-oriented one, and also by deciphering diagnostic stereotypes and acts of non-compliance during the hospital phase. This article proposes an analysis of anorexia in which social class is not limited to a set of values or representations, as is often done in social scientific studies of anorexia. It instead regards class practices, class dispositions, and class habitus not as causes, but, rather, as social conditions of possibility (or social conditions of likelihood) of the anorexic career.

\section{Methods}

This paper draws from research conducted in France from 1997 to 2001, based on repeated in-depth interviews with anorexic patients from two different hospitals (6 patients in Hospital H, 8 in Clinic C) and 5 months of observations of the everyday life and talk therapy sessions in the units they were hospitalized in, together with interviews with some of their teachers (11 interviews), snowball interviews of formerly diagnosed anorexics (3) and comparative interviews on body and food practices with high-school girls (11 interviews).

The persons interviewed as anorexic patients were all adolescent girls, and were all from upper and middle classes. Class membership was defined based on both parents' and grandparents' occupations and diplomas, which were obtained through a short questionnaire filled in by patients after each first interview. Data on parents were also 
accessible through medical records. The class membership in the sample ranged from Anne, whose father has a diploma from the French elite school system of 'grandes écoles' and is the head of a company (himself son a CEO of a major car company), and whose mother is an engineer, again with a diploma from a 'grande école'. Anne was coded as 'upper-class, with both cultural and economic capital'. At the other end of the spectrum, Sidonie's father has a high school diploma, owns a restaurant, and had parents who were skilled workers in the railway industry. Sidonie's mother did not finish high school, helps her father at the restaurant, and comes from a family of sewers. Sidonie was thus coded as 'middle-class from working class background, with more economic than cultural capital' .

Interviews began with a general question on the subject's 'experience with anorexia' and were conducted to allow a detailed description of the practices that constitute the anorexic career. In the course of observation, I paid close attention to the words that were used to classify, label and discuss pathologies and patients. Therefore, and somewhat untraditionally, practices have been gathered mainly through interviews, and categories and representations through observation.

\section{Looking for the Fifth Element}

As has been stated previously, the elusiveness of the Fifth Element (class) is merely relative to the intensive study on the other four elements. Social class is far from being altogether neglected in social scientific studies of anorexia But it has been mainly 
confined to three modes of appearance.

First, social class is often present as a factor in the quantitave epidemiology and etiology of anorexia. Epidemiologically speaking, from the 1960s to the 1980s there was great consensus towards the idea that anorexic patients came from upper- and middle-class families. Since the 1980s, this assumption has been questioned (for a review see Gremillion, 2003). Nonetheless, there are still convincing studies illustrating a positive correlation between anorexia nervosa and high socioeconomic status. For example, a recent retrospective survey over a 33-year period in the UK, based on an unusually large sample size of patients for this kind of studies (692) and using univariate analyses and logistic regression confirms that 'social class distribution was consistently weighted toward social classes $1 / 2^{\prime}$ from which came the majority of patients $(67,5 \%)$ (McClelland, Crisp, 2001).

Regarding this matter, there has been much discussion about the potential bias towards upper and middle classes conveyed by medical recruitment, modes of registration, diagnosis procedures and stereotyping as early as the 19th century (Brumberg, 1988) or more recently (Gremillion, 2003). Second to none in the identification of a specific class recruitment of anorexic patients, such analyses nevertheless leave open the question of the mechanisms through which membership in a class group plays a part in anorexia as a process and not only as a statistical datapoint. This process is precisely the issue that this paper will try to tackle.

Social class is secondly mentioned when a social trajectory, namely an upwardly mobile one, is thought to foster anorexia or eating disorders (Bordo, 1993 ; Gremillion, 2003). To 
the best of my knowledge, this claim has not been proven, since it may be very difficult to be sure about the upward mobility of young girls who have not yet achieved their final class status, or who have higher diplomas than their mothers, but in a context of growing education for women.

Finally, social class has been analyzed as shaping a set of values and attitudes that cause or, rather, facilitate, anorexia. This has been approached in three ways: by equating thinness and frailty with high social status and differentiation from lower classes, as early as the 19th century (Brumberg, 1988) as well as more recently (Gremillion, 2003); or because upper and middle classes mean higher education and educational achievement, which contradicts traditional female gender socialization and can therefore foster anorexia (Lawrence, 1987) or finally because a 'middle class context' — i.e., an emphasis on success at school or in the public domain or specific definitions of individuality and independence - by itself, or through conflict with other social norms, creates a pathway to anorexia (Turner, 1996 ; Evans et al., 2004).

This paper shares with these studies the claim that what constitutes anorexia can be related to a class position and context, while adding two contributions which endeavor to be more specific. First, a primary task of this paper is to specify 'what constitutes anorexia', and to locate it within a sociological framework as a 'deviant conversion career'. Second, while the primary focus on class has been on class representations and values, this paper takes them into account only as one element deriving from a class position, among others important factors such as class practices and class dispositions or class habitus. Following Bourdieu (1979), class position will thus be defined as a location 
in a 'social space' of class practices and judgments on practices - that is to say both a location in social hierarchies and in perceptions of social hierarchies.

\section{Anorexia as a deviant conversion career}

The idea of anorexia as a 'deviant career' (Becker, 1963) emerged from fieldwork analysis as a way of understanding the objective and subjective modifications that took place during subjects' experiences of 'anorexia' as it was described in interviews. It was useful to depart from 'conventions' on the subject, coming both from medical and psychological professionals and from 'experts by group membership' (anorexics) (Becker, 1998, p. 7; Author).

Previous studies have considered the concept of an 'anorexic career'. McLorg and Taub (1994) distinguish between three phases: 'Conforming behaviour', 'Primary Deviance', and 'Secondary Deviance', but focus primarily on the labeling process and its effects, rather than on the anorexic activity itself. Peters (1995) also distinguishes three phases in the anorexic career, the 'Diet Phase', the 'Ascetic Phase', and the 'Starvation Neurosis Phase', where the anorexic activity is more obvious (as their names show) but is tied to underlying, unconscious or mainly biological 'causes' ('a Pavlovian stimulus/response' or a 'starvation neurosis') that depart from the sociological imagination. In these two studies, what is left behind is precisely what this article focuses on: the anorexic activity itself, which can be seen as a self-conversion work. To paraphrase Ekins (1997) on 'male femaling', the anorexic conversion work similarly 'emerged as the single major social 
process being researched. It was pervasive and fundamental. It was patterned'. From early on, it was necessary (and illuminating) to recognize anorexics as girls who strenuously work on themselves at converting themselves in various domains, 'in various ways, in various contexts, at various times, with various stagings and with various consequences' (Ekins, 1997, p. 2). I identify four phases in the anorexic career, briefly defined as follows:

- Phase One is 'Commencement: the beginning of the commitment to transforming oneself'. The 'simple diet', which is commonly seen as the first step to anorexia, is but one element of this process which can include a wide range of transformation practices concerning the body (i.e., diet, haircut, change of style in clothing, change of sport or pace in the exercise regimen...) and concerning also culture at large (i.e., intensification of schoolwork, noticeable by teachers and which grade sheets bear witness to, selfmotivated reading programs or 'cultural' work-out sessions...). One subject, Yasmine, describes 'what happened at the beginning', in such a way that epitomises this multifaceted process of 'taking charge' of oneself:

'I thought to myself: you've got to grow muscle, you know, but I'm kind of lazy [she smiles] so at first I chose to lose weight, "you lose this huge bottom you have and nobody will see you're not fit" (...) and there was school, too. Even school subjects I used to hate, I was into them, I got into them, "nothing will stand in my way" (...). I threw myself into everything... Even sports, I used to hate sports since I was a kid, I hate that! But then, I tried hard, I threw myself into it, I became a straight-As sport student! (...) Also, I began reading. I mean real reading. Quite a lot of books, you know. I wanted to have an 
ironclad culture; I wanted to make one for myself. Before that, I used to read, but only what I liked and when I liked it. There I wanted to MAKE myself an ironclad culture (...) What else... Oh, clothes... I came to choose better outfits, more chic. Black slacks, tight tops, jackets, formal shoes... Quite classy... Hair well-done, make-up. '(Yasmine).

- Phase Two is 'Going on: keeping up the conversion'. A new type of work is engaged in, based on new techniques — first and foremost weight-loss techniques, but also techniques for measuring the effectiveness of the previous techniques - and on a rationalization of everyday life around this commitment and its different fields, corporal and/or cultural. It culminates with a new 'diet' in the original meaning of the word, a 'general conduct and organisation of life, including form of dress, behaviour and attitudes' (Turner, 1996, p. 176). This work makes it possible to remain 'in' the anorexic career. Habits are actually molded to meet this goal, and part of this new work is directly aimed at building and incorporating individual dispositions to make it possible and likely to continue, as described in these two excerpts:

'I didn't go directly from "eating normally" to "almost stopping eating" because it was not possible. What I did for a time was to eat a snack at five; when I came back from school, I ate OK, I drank milk, I ate cookies, so that I was not hungry at dinner and I could prevent myself from eating at dinner. And after that, snack was only every other day, and then every three days (...). There was food I ate a lot of, to be sick, so that I could be so disgusted by it that I would never eat it again. Just to make sure I was disgusted, and would never put them in my mouth again. That's how I came to like less and less kinds of food (...) I voluntarily disgusted myself, so that I wouldn't eat, so that I 
wouldn 't have any appetite for this kind of food' (Nadège).

'You realize you can get used to whatever you want to get used to (...) [Before anorexia] I used to enjoy candies, but I did manage to convince myself I was disgusted by it. I managed to say to myself: "You don't like that, you're disgusted by that, this is going to make you sick". Maybe there is some kind of pleasure, saying to yourself you can get used to everything' (Annabelle).

Here, incorporation is therefore the explicit aim of systematic work on body malleability and on deeply-rooted somatic sensations such as tastes and disgust. Furthermore, the interviewees describe a step-by-step process of learning to recognize and to enjoy the sensation of an 'empty stomach', and to loath 'feeling full'. This is why we can say they work and count on time, since the work they perform aims at enabling the body to go on 'by itself' and the person to stay on the anorexic path over time. During this second phase however, it slowly becomes a work of time on the person herself. Time is working on them because anorexic 'dispositions' are actually incorporated as a result of these repeated practices (Bourdieu, 1997; Lahire, 2003). New likes and dislikes, reflexes, representations ('it was beyond my control', 'When I looked at food, I didn't see food any more, I saw calories! And when I ate food, I just felt the calories on my tongue!') merge into a new set of dispositions which then become 'second nature' (Bourdieu, 1979; Wacquant, 1989). The existence of this new habitus is made obvious by exits from the anorexic career. Exits at the end of the first phase are easy; all of the high-school interviewees who tried to lose weight just 'gave up'. Leaving the anorexic career at the end of the second phase, as some snowball interviewees who were never hospitalized did, 
is different from just 'giving up' because it involved a whole new, and reversed, work on oneself, a new conversion back to previous dispositions. This illustrates that an anorexic set of dispositions has been incorporated and must be fought and overcome.

- Phase Three is still about 'Going on', but the commitment has now to be sustained in spite of whistle-blowers and the surveillance network that has gradually woven around the young girls. More and more people (family, friends, teachers, doctors...) are watching more and more aspects of their lives (diet practices, but also physical exercise, use of bathroom scales, or school work, which is, at some point, interpreted through medical categories as 'hyperactivity'). A new and specific work emerges in response to this surveillance: a 'discretion work', designed to make problematic actions less perceptible, followed by 'illusion work' which aims at making them invisible.

- Phase Four is the Hospital phase: in this phase, the hospital has to deal with the anorexic habitus as it has been constructed throughout the first three phases. The hospital work is about reversing the anorexic commitment by redefining it as pathological, negotiating the acknowledgment of its pathological nature with the patient, and obtaining her participation in a new - and now collective - conversion work, initiated this time by the medical institution itself, defined as a way 'back to normality' — which can have various meanings depending on the therapeutic orientation of the medical unit.

\section{The social space of the anorexic conversion}

As an analytical tool, the notion of career can be used to 'turn people into 
activity' (Becker, 1998), and to a transition from a definition of 'identity' to a one of action: one is not born an anorexic, one must become one, and to 'be' (labeled) anorexic, one has to 'do' the things detailed above. Drifting away from the traditional use of the notion of career in sociology, this paper purports to show that to 'do' those things, you have to 'be' somebody specific. This paper demonstrates that the characteristics of the anorexic career echo those of its recruitment groups, age, gender, and especially, in this paper, social class. This deviant conversion career can therefore be related to the 'social space of social classes' it moves in, and the behaviours seen as resulting from, or typical of, the pathology are interpreted as social practices located in such a space.

\section{1) A class-situated set of practices, attitudes and values}

First, if we analyse what constitutes the anorexic career as a set of practices like any other set of practices, we see that they are located in a specific place within the social space: anorexic food practices, body practices and school practices are those of the upper and middle classes, and more specifically those who have more cultural than economic capital.

One key example of this is found in food consumption. The idea here is to compare what seems to be 'anorexic' food practices, that is to say behaviours that seem specific to anorexia, with their 'normal' counterparts, and to locate them within the social space of food consumption. The data Bourdieu used to draw the social space of food consumption in La Distinction is dated, but recent statistical studies show that food consumption is still strongly class-based today in France. Therefore, the notion of class tastes and food 
dispositions still stands, and it is possible to compare the description of food consumption in the interviews with statistics available on food consumption in France around the 1990s (to eliminate evolutions and differences linked with national specificities and historical changes). In particular, what the interviewees eat and what they don't eat is not chosen randomly, or only according to the calorie intake of each food. They mentioned for example 'living on' green apples, grapefruits, greens and vegetables, non-fat yoghurts, lean meats, fish and seafood, 'simple' food but also sometimes exotic ones such as 'curry gambas'. These selections reveal 'dominant tastes' (Bourdieu, 1979) for they single out foods that are consumed in greater amounts by upper classes in France today, such as fish, fruits and vegetables, light dairy products or exotic food (Herpin, Manon, 1997; Grignon, Grignon, 1999; Cavaillet et al., 2004). 'Restrictive' anorexia is therefore not only about 'restricting' food: it is about choosing a certain type of food, with certain properties, both caloric and social, at the expense of another. Foods that are refused are those that are strongly associated with working-class tastes, such as bread, charcuterie, or plats en sauces. As Grignon and Grignon (1999, p. 168) say about 'regular' food practices, 'among foods reputedly fattening, one more often avoids reputedly 'common' foods, that is to say foods overconsumed by farmers and blue-collar workers, which act as a foil and become scapegoats'. In some cases, social properties of foods can even be isolated from caloric properties, despite the fact that 'dominant taste' is often a taste for light foods. For example, the interviewees repeatedly described using large amounts of hot liquid as a stomach-filling zero-calorie snack, but they always mentioned tea, and not coffee. Tea and coffee seem technically identical, but one of them - tea - is very 
specific to French upper-classes today, while the other is not (Cavaillet et al., 2004).

The way food is chosen is also very telling:

'I selected food based on what it looked like... It had to be things that were pretty to look at, that weren't gross' (Nadège).

'My aunt and my uncle, when they saw me like that, they tried to take me out to very

fancy restaurants. They knew me quite well... And in fact, it worked! I was actually eating in those places, even if it meant not eating three days before and three days

after!' (Véronique).

Aestheticising food and meals as described above (rather than eating them), throwing away food or leaving it on a half-finished plate, displaying self-restraint and 'substance relegation' (Bourdieu, 1979) by 'forgetting' to eat or 'not being hungry': all these dispositions are stereotypical habits of the upper and middle-class and are clearly in opposition with working-class ones (Boltanski, 1969; Grignon, Grignon, 1980; Schwartz, 1990). A similar connection can be shown to exist between anorexic sport and school practices and those of the upper and middle-class in these fields (Author). Therefore, seemingly 'typically anorexic' practices, however pathological they may appear, clearly echo their 'normal' and class-biased counterparts.

\section{2) A class-based ethos}

Furthermore, if we now turn to the 'anorexic ethos', it also reveals close allegiance with specific upper and middle-class attitudes and values. For example, the corporeal asceticism anorexics display is also a corporeal elitism that distinguishes lower-class 
body configurations and hexis as both crude and loose. It constructs corporeal capital as a 'total capital', which can, so to speak, incorporate and express cultural capital:

'I knew I was skinny, I knew it. But it was not enough for me. I knew that for other people, it wasn't nice, but to my eye it was... my eye was different and I felt happy to cultivate this difference (...) I remember I felt the utter despise for people who thought food meant congeniality (...): the very image of a lack of control and letting oneself go (...) There was one part of my family where there were... three sisters who were... fat... crude... ugly ... silly! [She laughs] It went together. And to me, the appearance went together with the intellect, the thinner I was, the smarter I was [the word fine she uses means both "thin" and "smart" in French] (...) When I was anorexic, this is very strange, but I felt... I felt really at ease speaking, thinking... I felt gifted... And now, it's funny but I don't feel that way any longer, as if giving up anorexia had also meant giving up on the intellectual ground' (Véronique).

Such a resemblance between the anorexic world view and the upper and middle-class one can also be found in the constant display of an ethos of control over corporeal destiny which contrasts with a more fatalist body acceptance in the working classes (Featherstone, 1987; Schwartz, 1990). This ethos is all the more salient among the interviewees in that they are young and female, and therefore belong to two other groups who share this conception of the body and of the self as linked together and as structurally 'unfinished' businesses (Author). The interviewees' discourse additionally bears witness to the existence of a more general ethos of control over social destiny which is clearly that of middle and upper classes. This ethos might be opposed to the 
working-classes 'taste for chance', seen in how the anorexics' favourite game, described below by Camille, can be opposed to working-class preferences for lottery and games of chance (Hoggart, 1957; Weber, 1989):

'This is very difficult for me to accept what I can't control, what I don't know, what comes by chance, what is "like that", (...) what comes around even if I didn't look for it' (Christine)

'At the hospital, we [anorexics] were playing checkers. It was not your usual checkers, it was much more complex, we were going very fast, the idea was to make one's way very fast so that the opponent could not see it and could do nothing about it, we were real checkers champs at X [a unit specialised in the treatment of anorexia] !' (Camille).

Such an urge for control is usually analyzed through psychological or psychiatric diagnoses, but it arrives at a new meaning when tied to class position and habitus. The social space in which the anorexic career develops is therefore made perceptible by taking into consideration the location both of the practices that constitute the anorexic career and of the ethos it displays. It moreover appears in the orientation of it as selftransformation work — but a transformation into what?

\section{3) A class-oriented conversion}

This section demonstrates that the self-conversion at issue is one oriented towards the upper regions of social space by focusing again on body and food practices (for a similar analysis on sport, school and cultural practices, see (Author)).

First and foremost, losing weight is understood as a step up on the feminine social ladder, 
since the higher one's social origin and occupation, the lower one's weight - this being true in France for women (Bodier, 1995) and adolescent girls (Peretti, Castetbon, 2004), with a strengthening of these social patterns since the 1980s (Saint-Pol, 2007).

Second, the result of the self-transformation that takes place during the first phases of the anorexic career is the acquisition of dominant habits and practices: dominant taste for foods, as when Priscille or Emily describes a 'before [anorexia]' liking of 'Mac Donald's', fries, sausages, and an 'after' [during anorexia] liking for fish, seafood, or oysters; or when Yasmine or Louise refer to a make-over involving the dominant clothing syle (i.e., more slacks, formal shoes, skirts and dresses, but fewer jeans, tee-shirts and sneakers). Somatic sensations themselves are the object of such 'upwardly work'. We recall that the interviewees had to learn (or teach themselves), step by step, to be disgusted by greasy or sugary food, to enjoy the sensation of an 'empty stomach,' or to loath 'feeling full'. This can be seen as incorporating a dominant somatic culture involving dislike or even nausea for feelings of repletion, contrary to the satisfaction expressed about these sensations by members of the working classes (Boltanski, 1971). What is produced through the first phases of the career is therefore a new and dominant 'body use' [usage du corps] that goes down deeply to somatic sensations themselves. It is shaped through a more and more extreme repression of working-class tastes or body uses that were present before. The anorexic career might therefore be described as an upward trajectory in the 'universe of class bodies' (Featherstone, 1987, p. 125) and even in the universe of deep-down class sensations. Moreover, the very existence of this work is downplayed by the interviewees, which bears witness to their adherence to the dominant model of a thin body obtained by 
'miracle' rather than through crude 'hard work' (Bourdieu, 1979):

'I was trying to give the impression I ate normally, because I wanted to pretend I was thin while eating. That was the message I was trying to send: I was thin but I ate normally, or even I ate more than people usually do, I wasn 't thin because I did not eat...' (Louise). The first three phases of the anorexic career and their self-transformation process are thus, deeply shaped by the social space in which they develop. Yet, once in the hospital, will this social space of social classes give way to solely medical dimensions?

\section{The social space of the hospital phase}

Medical institutions, in which the last phase occurs, are actually far from neutral spaces in regards social class.

\section{1) Anorexia and bulimia as social-class stereotypes}

It can first be argued that diagnoses of eating disorders involve social-class stereotypes by which anorexia nervosa is implicitly associated by physicians with upper-classes and bulimia nervosa with lower-classes.

Such an underlying social space appears in classical clinical texts on eating disorders, such as the following excerpt by Hilde Bruch in which true social 'prestige' is attributed to anorexics while bulimics are almost explicitly associated with financial need and even delinquency:

'[Bulimics] make an exhibitionistic display of their lack of control or discipline, in 
contrast to the adherence to discipline of the true anorexics... The modern bulimic is impressive by what looks like a deficit in the sense of responsibility (...). Though relatively uninvolved, they expect to share in the prestige of anorexia nervosa. Some complain about the expense of their consumption and will take food without paying for it' (Bruch, quoted in Gordon, 1990, p. 135).

This social distribution also comes into play in the everyday medical discourse within the therapeutic units, such as when 'typical' anorexic patients are described with attributes that are those of the upper and middle-classes:

'At coffee break, a psychologist comes to me and says: "Oh, I had to tell you, today I saw a very typical anorexic girl! She spoke to me about school, of course! I asked her: what else, than school? Well, she spoke to me about playing the piano! What else? Well, ballet of course! School, the piano, ballet: a nice young lady like they used to make them in the good old days!", ' [Fieldnotes].

'Sense of repartee', 'very subtle in the interaction', 'articulate', 'sharp' [Medical records, on anorexic patients]

Furthermore, 'typical anorexic families' are commonly described as composed of a 'feminine' father - that is to say, one closer to upper and middle-classes definitions of masculinity —and an 'often professional over-ambitious mother'. These families are strongly distinguished from 'typical bulimic families' as counterparts to one another in a way that suggests social-class stereotypes and oppositions:

'Typically, anorexics'families are families where people don't show off their feelings and don't go into open conflicts, they have nothing to do with bulimics'families, which are 
overfighting, very unstable, no organisation, no stability, lots of shouting... it's a picture and its negative. In the family interview with Alexandra [a bulimic patient] and her family, they were shouting, they were ripping their heads off...' [Staff meeting, Fieldnotes].

Finally, this opposition between anorexics and bulimics (and, indeed, their families) and its social connotations make their way into the patients' discourse, where anorexia is attributed greater social prestige than bulimia, and therefore becomes an almost likeable, or at least preferred, stigma in comparison, even for a young girl who didn't accept the anorexic label at first:

'I would not acknowledge I was anorexic... But this friend asked me: "but are you bulimic or anorexic?", and I said "no!", "no!, I'm no bulimic, I'm anorexic, OK ?” The idea I was purging was unbearable... It was dirty and sick, whereas anorexia ... anorexia, it's like being a delicate flower, isn't?, and that's it' (Anne).

This hierarchy between anorexia and bulimia could explain some of the aforementioned biases towards upper and middle classes conveyed by diagnosis procedures, but may also be interpreted as a medical perception of the social attributes linked with the social class status of their patients. The latter becomes more obvious in a close-up on a particularly difficult patient, described below.

\section{2) A class-based resistance to medical control}

Anorexic patients are well-known for their 'resistance' to the hospital's actions and point of view. They are generally defined as 'difficult', 'non-compliant', and 'resisting' 
patients, and are depicted as such at the fieldwork sites of this research. This resistance is generally interpreted as psychological and, importantly, is linked to mental pathology. It can however be illuminating to look at such resistance as a social will and way of acting, made possible by distinctive class resources. This is not to say that only upper and middle class patients can display a resistance to medical power. But the specific ways in which anorexic patients resist medical power is not absent of social class dispositions and attitudes.

This can be illustrated by focusing on a single case, informed both by the two interviews with the young girl and thorough observation of her stay at the hospital. During the 5 months of observation, three anorexic patients were deemed as 'particularly noncompliant' with Camille, a 17 year-old patient from Clinic C, as the one recognized as the most difficult. Camille is the daughter of a communication consultant and a medical doctor, both with high-level diplomas, placing Camille at the first tier of the sample in terms of class. Since she turned 14 years old, Camille has been in and out of hospitals under the diagnosis of restrictive anorexia nervosa. Her medical trajectory (its length and variety) has obviously provided her with a deep insider's knowledge of the medical institution. She employed this professionalisation as a patient (Barrett, 1996, p. 162) as a strategic weapon in the 'serious game' (Goffman, 1961) of resisting medical intervention and point of view. But it might be argued that her relation to the hospital is also shaped by her cultural and symbolic capital. For example, she speaks with irony of Clinic $\mathrm{C}$ as the 'hotel-restaurant-school' she is living in, while insisting that the services offered by this institution do not deserve her patronage. In contrast with difficult patients studied by 
Barrett (1996), Camille is not so much 'using the place as a motel' (Barrett, 1996, p. 162) than as an overrated deluxe hotel! :

'When I first came here, into this room, I had my blanket changed, it was a lousy purple one, I had it changed to this green one (...) I told him [the well-known specialist of anorexia who used to treat her in his high-profile hospital], your hospital is a lousy place, it is very depressing for me to go to such a lousy place' (Camille) '17. 09 : Camille is very unhappy about her room, she thinks it's too small. 10. 11 : Clinical interview: Camille is very provocative and aggressive towards [the head psychiatrist]. She threatens to leave the hospital if she is not given a better room' [Medical and nurses records].

Additionally, Camille constantly voices contempt for the members of the treatment team who are not doctors:

'Camille had an appointment at 1: 15 with Carole [a nurse]. She just forgot! I reminded her of it, she was nearly arrogant' [Nurse record]

'Camille is interacting only with the medical team and she gives the silent treatment to the nurse team $=>$ why?' [Nurse record]

'When asked "why", she replied that her grandmother - who used to be a journalist in a famous newspaper — taught her to "rather talk to God than to His saints" [a French saying]' [Staff meeting record].

If this contempt for both the 'lousy' hospital and the 'subordinate' nurses can be explained by her class position, as are her attitudes towards doctors, with whom she combines a daring fighting spirit with a form of class solidarity and connivance (both of which she 
may well be exaggerating during the interview, though doctors acknowledged she had 'stood up to $\mathrm{Y}$ ' and thrown him off balance):

'I told Y [her previous therapist, a well-known specialist of anorexia] : "you stopped saying anything interesting during sessions long ago, you don't understand anything any longer, your theater stuff [the psychiatrist is using psychodrama as a therapeutic method] is so silly, I'm so fed up of humoring you"... I stood up to leave the room, he tried to prevent me from doing it, so I said: "Oh this is what your idea of freedom of speech boils down to! You will never see me again", it lasted two months, he was writing to me every week, I finally accepted to sit with him, and we talked, but I did not accept to go on therapy with him (...) I never spoke to him since' (Camille).

'I finally met with $\mathrm{Mr} X$. [Dr X, a head psychiatrist at Clinic C], and he seemed OK, quite nice. And he told me: "you come whenever you want, there will be a place for you", and usually you wait one or two years before hoping for a vacancy here, and only three days after was I accepted! Actually, there must have been a phone call from Y that may have eased things a bit...' (Camille)

Camille is the one who makes decisions about the beginning, the end and the particular techniques used in her treatment. She is the one who decides what is 'interesting' and what is not. She is the one giving the 'silent treatment' to the nurses while enjoying 'special treatment' for herself. This radical overturn of the doctor-patient power relation is all the more striking because it initiates from a young girl (some of the stories she describes happened when she was 14 or 15 years old), confronting senior male doctors. It might therefore be seen that social class dispositions (such as self-assurance, a sense of 
entitlement, familiarity with the medical world which her mother belongs to, or a relation to 'speech' and discourse that comes with a high level of cultural capital) can account for Camille's challenges to medical authority, as well as the specific forms her challenges take.

\section{Conclusion}

Epidemiological research has identified a significant association between upper or middle class membership and a woman's probability of becoming anorexic, but the extant literature has yet to address the social processes underlying this association. In order to fill this gap this paper has proposed understanding anorexia as a deviant career - a career that is a conversion into an anorexic set of practices and orientations that can be understood as a distinctive type of Bourdieuian habitus. This paper has argued that this set of practices and orientations reflect strong resonances with practices and orientations clearly identified with middle and upper class status.

Such an argument should not be interpreted to mean that anorexia cannot, or does not, exist among members of the working classes. On the contrary, this approach provides a structure from which to analyse such cases as 'atypical' in terms of social class, or, alternatively, as signs of diffusion of representations or practices from one social location to another. This inscription of the anorexic career in a social space is also not to be equated with the explanation of eating disorders as related to family socialization; it nevertheless defines a 'locus' where the very practices of anorexic conversion find facilitating dispositions. This is not understood as causes per se but, rather, social 
conditions of possibility or of likelihood.

The model offered has been constructed by combining two sociological traditions - a symbolic interactionist approach and a bourdieuian approach - that are usually deemed incompatible. The symbolic interactionist approach to deviant careers is seen as powerful in putting in plain light the processual dimension of social life, the meaning people give to their activity, and the way such activity is seen and labelled by others. Yet it is also said to evade questions of the structural determinations of practice. Conversely, the bourdieuian approach to practice is seen as paramount in revealing hidden and underlying social influences, par excellence those of social class, but it is often said to lack an analysis of the activity itself. The theoretical articulation used in this paper (career and habitus, process and structure, label and class) is offered here as a way to take the best of two worlds.

\section{REFERENCES}

Barrett, R. (1996) The Psychiatric Team and the Social Definition of Schizophrenia. Cambridge: Cambridge University Press.

Becker, H. S. (1998) Tricks of the Trade. How to think about your research while you're doing it. Chicago: University of Chicago Press.

Becker, H. S. (1963) Outsiders. New York: The Free Press of Glencoe.

Bodier, M. (1995) 'Le corps change, son image aussi', INSEE Première 356 : 1-4.

Boltanski, L. (1971) 'Les usages sociaux du corps', Annales E.S.C., 26 (1) : 205-233. 
Boltanski, L. (1969) Prime éducation et morale de classe. Paris: EHESS.

Bourdieu, P. (1997) Méditations pascaliennes. Paris: Seuil.

Bourdieu, P. (1979) La Distinction. Critique sociale du jugement. Paris: Minuit.

Bordo, S. (1993) Unbearable weight. Feminism, Western Culture, and the Body.

Berkeley: University of California Press.

Brumberg, J. J. (1988) Fasting Girls. The History of Anorexia Nervosa. Cambridge: Harvard University Press.

Cavaillet, F. Darmon, N. Lhuissier, A. and Régnier, F. (2004) L'alimentation des populations défavorisées en France, Ivry sur Seine : INRA-Corela, Document de travail $n^{\circ} 2004-9$.

Ekins, R. (1997) Male Femaling. A grounded theory approach to cross-dressing and sexchanging, London: Routledge.

Evans, J., Rich, E. and Holroyd, R. (2004) 'Disordered eating and disordered schooling: what schools do to middle class girls', British Journal of Sociology of Education, 25 (2): $123-142$.

Featherstone, M. (1999) ‘Body Modification: An Introduction', Body and Society 5 (2-3): $1-13$.

Featherstone, M. (1987) 'Leisure, Symbolic Power and the Life Course', in Horne, J., Jary, D. and Tomlinson, A. (eds) Sport, Leisure and Social Relations. London: Routledge: 113-138.

Goffman, E. (1961) Asylums. Essays on the Social Situation of Mental Patients and Other Inmates. Garden City (New York): Doubleday. 
Gooren, H. (2005) 'Towards a new model of conversion careers: the impact of personality and contingency factors', Exchange, 34 (2): 149-166.

Greil, A. L. and Rudy, D. L. (1983) 'Conversion to the World View of Alcoholics Anonymous: A Refinement of Conversion Theory', Qualitative Sociology 6 (1): 5-28.

Gremillion, H. (2003) Feeding Anorexia: gender and power at a treatment center, Durham and London: Duke University Press.

Grignon, C. and Grignon, Ch. (1999) 'Long-term trends in food consumption: a french portrait', Food and Foodways 8 (3): 151-174.

Grignon, C. and Grignon, Ch. (1980) 'Styles d'alimentation et goûts populaires', Revue française de sociologie 21(4) : 531-569.

Herpin, N. and Manon, N. (1997) 'Approvisionnement, menus et obésité dans les foyers les plus pauvres', in Lollivier, S. and Verger, D. 'Pauvreté d'existence, monétaire ou subjective sont distinctes', Economie et Statistique n $308-309-310$ : 117-118.

Hoggart, R. (1957) The Uses of Literacy. Aspects of working-class life with special reference to publications and entertainments. Londres : Chatto \& Windus.

Lahire, B. (2003) 'From the habitus to an individual heritage of dispositions. Towards a sociology at the level of the individual', Poetics, Journal of Empirical Research on Culture, the Media and the Arts 31: 329-355.

Luhrmann, T. M. (2000) Of Two Minds. The Growing Disorder in American Psychiatry. New York: Alfred A. Knopf.

MacSween, M. (1993) Anorexic Bodies. A feminist and sociological perspective on Anorexia Nervosa. London: Routledge. 
McClelland, L. and Crisp, A. (2001) 'Anorexia and Social Class', International Journal of Eating Disorders 29 (2): 150-156.

McLorg, P. A. and Taub, D. E. (1987) ‘Anorexia Nervosa and Bulimia: The Development of Deviant Identities', Deviant Behavior 8, republished in Adler, P. A. and Adler, P. (1994) Constructions of Deviance: Social Power, Context, and Interaction. New York: Wadsworth: 249-261.

Peretti, Ch. de and Castetbon, K. (2004) 'Surpoids et obésité chez les adolescents scolarisés en classe de troisième’, Etudes et résultats DREES, $\mathrm{n}^{\circ} 283$.

Peters, N. (1995) 'The ascetic anorexic', Social Analysis 37: 44-66.

Pinçon, M. and Pinçon-Charlot, M. (2000) Sociologie de la bourgeoisie, Paris: La Découverte.

Régnier, F. Lhuissier, A. and Gojard, S. (2006) Sociologie de l'alimentation, Paris: La Découverte.

Saint-Pol, T. de (2007) 'L'obésité en France: les écarts entre catégories sociales s'accroissent', Insee Première $\mathrm{n}^{\circ} 1123$.

Schwartz, O. (1990) Le monde privé des ouvriers. Hommes et femmes du Nord, Paris : Presses Universitaires de France.

Shilling, C. (1993) The Body and Social Theory. London: Sage.

Turner, B. S. (1996) The Body and Society. Explorations in Social Theory, London: Sage. Wacquant, L. (1989) 'Corps et âme. Notes ethnographiques d'un apprenti-boxeur', Actes de la recherche en sciences sociales, 80 : 33-67.

Weber, F. (1989) Le Travail à-côté. Paris : Editions de l'EHESS-Inra. 
